\title{
EL FIDEICOMISO: SU REGULACIÓN EN EL DERECHO ARGENTINO Y LAS VENTAJAS DE LA SECURITIZACIÓN DE CRÉDITOS POR MEDIO DEL FIDEICOMISO FINANCIERO
}

SERGIO JUNIORS SHWOIHORT

FACULTAD DE DERECHO Y CIENCIAS SOCIALES Y POLÍTICAS - UNNE 


\title{
RESUMEN
}

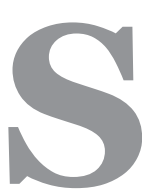

in lugar a dudas que uno de los contratos modernos que mayor difusión ha alcanzado en nuestro país en los últimos tiempos, es el de fideicomiso, el cual ha sido elegido, principalmente, para formalizar actividades empresariales (sean de producción, industrialización, construcción o comercialización), sin perjuicio de otras utilizaciones. Esto lleva a la necesidad de analizar este instrumento contractual de manera general, y a hacer hincapié en una de sus clases, cual es el fideicomiso financiero, utilizado como uno de los vehículos para la securitización de activos en general y créditos en particular, actuando como una herramienta eficiente de posicionamiento y palanca financiera de las grandes empresas. En fin, esta modalidad contractual tiene innumerables ventajas, pero también peligros sobre los cuales hay que poner atención, principalmente atendiendo a la experiencia de otros países, por lo que se debe continuar con el análisis de los distintos aspectos de este contrato para mejorar la institución en nuestro sistema, evitando caer en los mismos errores, y garantizando de este modo la mayor seguridad jurídica y económica posible en su utilización. La presente labor, tiende a contribuir en algo con ello.

Palabras clave: fideicomiso - contratos - securitización.

\begin{abstract}
Undoubtedly that one of the modern contracts that more diffusion reached in recent times in our country is that of trust, which has been chosen mainly to formalize business (whether of production, manufacturing, construction or marketing ), without prejudice to other uses. This leads to the need to analyze this contractual instrument in general, and to emphasize one of his classes, which is the financial trust, used as a vehicle for the securitization of assets in general and credits in particular, acting as a efficient tool of positioning and financial leverage for large firms. Finally, this type of contract has many advantages, but also dangers for which we must pay attention, especially taking into account experience of other countries; so that should be continue with the analysis of various aspects of this contract to improve the institution in our system, avoiding fall the same mistakes, and thus ensuring the highest possible legal and economic security in their use. This work tends to contribute something to it.
\end{abstract}

Keywords: : trust - contracts - securitization.

\section{INTRODUCCIÓN}

Si se nos preguntara por cualquier motivo que fuere, aunque solo sea por mera curiosidad, qué contratos han incrementado su participación en el mundo negocial de los últimos tiempos en nuestro país, deberíamos incorporar en la respuesta, sin lugar a dudas, al contrato de fideicomiso. 
El mencionado instrumento, si bien tiene una larga data de existencia en el Derecho Comparado, al punto que sus orígenes más remotos se remontan al Derecho Romano, ha cobrado en los últimos años un impulso digno de ser destacado, principalmente para formalizar actividades empresariales (sean de producción, industrialización, construcción o comercialización). El mismo ha sido una de las opciones por excelencia de los emprendedores y empresarios para ello, lo cual ha llevado al fideicomiso a constituirse en un contrato sumamente usual.

En este sentido, y sin restar importancia a otras clases de fideicomiso -primordialmente el de administración- interesa resaltar la importancia y las ventajas que trae aparejada la utilización del fideicomiso financiero como herramienta de securitización de los créditos, que ha contribuido enormemente con el incremento del capital de conocidas empresas.

Con base en las consideraciones expuestas, en el decurso del presente trabajo se abordará el contrato de fideicomiso, definiéndolo, mencionando sus principales antecedentes y analizando la regulación del mismo en la legislación argentina. Asimismo, se describirá brevemente a que se hace referencia cuando hablamos de "securitización" de créditos, para centrarnos finalmente en una de las modalidades, constituida por el contrato de fideicomiso financiero.

\section{ANTECEDENTES DEL CONTRATO DE FIDEICOMISO}

Se dijo anteriormente que el fideicomiso tiene larga data. En este sentido, su antecedente más remoto se remonta al Derecho Romano donde existían dos institutos vinculados con él: la fiducia y la herencia fideicomisaria (que luego fue confundiéndose con los legados).

Conforme lo señala Ferretti (1992), la fiducia se basaba "en la enajenación de una cosa corporal en virtud de la mancipatio o la in iure cessio, con el fin de otorgar al acreedor una garantía real. El acreedor quedaba obligado a restituir la cosa al mancipante o al cedente cuando su crédito hubiere sido satisfecho por el deudor, y para que éste pudiera exigir restitución de la cosa dada en fiducia se sancionó la actio fiduciae. Además, mediante un pacto (pactum fiduciae) se solían regular las modalidades de la restitución misma".

La finalidad de la figura aludida en el Derecho Romano, se asemeja mucho a la mantenida en la actualidad por el fideicomiso en garantía que veremos infra.

Por otro lado, existía la denominada herencia fideicomisaria, regulada de manera específica en el Libro II, Tomo XXIII del Corpus Iuris Civilis ${ }^{1}$.

La primera parte de esta antigua norma, contiene un resumen casi inmejorable de los antecedentes del fideicomiso, al decir que “...ha de saberse que en los primeros tiempos eran nulos todos los fideicomisos, porque nadie era obligado contra su voluntad á cumplir aquello que se le había rogado; pues si dejaban herencia ó legados á aquellos á quienes no podían dejarlos, los confiaban á la fidelidad de los que podían recibir por testamento: y por esto se llamaron fideicomisos, porque no se apoyaban en ningún vínculo de derecho, sino tan sólo en la honradez de los que eran rogados. Después, el divino Augusto fue el primero que, movido alguna que

\footnotetext{
${ }^{1} \mathrm{Al}$ cual se puede acceder consultando la excelente, trabajosa y ya centenaria obra de D. Ildefonso L. García del Corral -quien fuera Licenciado en Derecho Civil y Canónico, en Filosofía y Letras y Abogado de los ilustres Colegios de Barcelona y Madriddenominada Cuerpo del Derecho Civil Romano, Primera Parte, Ed. Jaime Molinas, Barcelona, año 1889, del cual se han extraído los textos que se transcriben en el presente.
} 
otra vez por consideración á las personas, ó porque alguien se dijese rogado por la salud de él mismo, ó por insigne perfidia de ciertos individuos, mandó á los cónsules que interpusiesen su autoridad. Y como esto parecía justo y era popular, se convirtió paulatinamente en jurisdicción permanente; y tanto creció el favor de ellos, que poco á poco se creó también un pretor especial, que fallase en materia de fideicomisos, al que llamaban fideicomisario...”.

Sin perjuicio de las demás reglas citadas en la normativa a la que se viene aludiendo -en cuanto a funcionamiento, responsabilidades de los sujetos intervinientes y acciones que de ella podían derivarse, entre otras-, la delimitación de los sujetos que intervenían y la forma en que operaba el instituto surge claramente del texto siguiente: "Ha de saberse, pues, ante todo, que es necesario que álguien sea instituido heredero en un testamento otorgado en derecho, y que á su fidelidad se confie que restituya á otro aquella herencia; pues por lo demás es nulo el testamento en que nadie es instituido heredero. Así, cuando alguno hubiere escrito: «sea heredero Lucio Ticio» podrá añadir: «te ruego, Lucio Ticio, que tan pronto como puedas adir mi herencia, la entregues y restituyas á Gayo Seyo» Mas también puede cualquiera rogar á su heredero que restituya una parte; y es libre de dejar el fideicomiso ó puramente, ó bajo condición, ó desde día cierto... Además de esto, también puede el que haya de morir intestado rogar á aquel á quien cree que pertenecen sus bienes ó por derecho civil ú honorario, que restituya á alguno toda su herencia, ó parte de ella, ó alguna cosa, como un fundo, un hombre, ó dinero, como quiera que no sean válidos los legados sino por virtud de testamento... También puede rogar á aquel á quien se restituye alguna cosa, que á su vez restituya á otro la misma cosa, ó íntegra, ó en parte, ó aún otra diversa”.

Como puede apreciarse, de los fragmentos transcriptos, surgen las diferentes variantes que podían darse en esta clase de fideicomiso.

Finalmente, el fideicomiso hereditario podía -además de constituirse sobre todo o una parte representativa del patrimonio del causante- efectuarse sobre bienes determinados, posibilidad que surgía del Libro II, Título XXIV, denominado "De los objetos particulares dejados por fideicomisos", que en su parte inicial establecía que "Mas puede cualquiera dejar también por fideicomiso objetos particulares, como un fundo, un hombre, un vestido, plata, moneda acunada; y rogar ó al mismo heredero ó al legatario que lo restituya á otro, por más de que no pueda legarse por medio del legatario".

No obstante los antecedentes mencionados en el Derecho Romano, que son sin lugar a dudas de trascendencia, es en el Derecho Anglosajón donde se encuentran las bases más firmes de la estructura actual de este contrato, principalmente en el trust, que al decir de Icazatti (2011) "se considera, en muchos aspectos, la contribución más innovadora en el sistema jurídico inglés”.

La palabra trust significa confianza. Es justamente ello lo que constituye la base de esta clase de contratos, en los cuales una de las partes deposita parte de sus bienes o encomienda la administración de sus negocios en otra, basada en esa confianza o seguridad que la otra le inspira.

Esta particular relación jurídica se establece entre el settlor, quien es el que da nacimiento 
u origen al trust, mediante la entrega de los bienes que constituirán su objeto; sería el fiduciante en nuestra legislación. El trustee, que es la persona a la cual se transmite la propiedad legal de los bienes, y que se constituye en responsable del cumplimiento del encargo otorgado por el settlor. Es el equivalente al fiduciario en nuestro Derecho; y, finalmente, el cestui que trust, que es la persona en favor de quien se constituyó y funciona el trust, es decir, el beneficiario.

Desde el Derecho Anglosajón, la figura del trust se desperdigó a distintas legislaciones del mundo (con un desarrollo muy importante en Francia y México, sin perjuicio de otros países), con la denominación más común de fideicomiso, con diferentes modalidades, principalmente diferenciadas en cuanto a las exigencias requeridas para constituirse como fiduciario ${ }^{2}$, o bien por los efectos del mismo en cuanto a si existe o no transferencia de la propiedad mediante la celebración del contrato; cuestiones que no se abordarán, por exceder su objeto de análisis del presente.

\section{REGULACIÓN EN LA LEGISLACIÓN ARGENTINA}

Si bien el Código Civil Argentino, refería al dominio fiduciario en el Art. 2662 -al disponer que el "dominio fiduciario es el que se adquiere en un fideicomiso singular, subordinado a durar solamente hasta el cumplimiento de una condición resolutiva, o hasta el vencimiento de un plazo resolutivo, para el efecto de restituir la cosa a un tercero"- es con la sanción de la Ley 24.441 de "Financiamiento de la vivienda y la construcción, que la figura del fideicomiso se regula inicialmente en nuestro Derecho, dándole la forma que tiene actualmente, modificando la disposición del aludido artículo del Código Civil que fue reemplazada por la que analizaremos en el punto siguiente, al tratar el concepto y los caracteres de este contrato.

Asimismo, la regulación del fideicomiso no se resume en las disposiciones de la Ley 24.441, sino que la misma es completada por el Decreto $\mathrm{N}^{\circ} 780 / 95$ que la reglamenta.

Además, existen otras normas (ya sean de regulación, arancelarias, impositivas o de control) en nuestro Derecho positivo que influyen sobre el fideicomiso, como son: la Ley $\mathrm{N}^{\circ} \mathbf{2 5 . 2 8 4}$ de Entidades Deportivas, que establece un régimen especial de administración -mediante el fideicomiso de administración con control judicial- de este tipo de entidades cuando padezcan dificultades económicas; la Resolución General N 368/2001 de la Comisión Nacional de Valores que regula cuestiones relativas a los fideicomisos; el Decreto $\mathrm{N}^{\circ} 78 \mathrm{o} / 95$ que regula los aspectos generales tributarios sobre fideicomisos, del impuesto a las ganancias y sobre los bienes personales; el Decreto $\mathrm{N}^{\circ} 1526 / 98$, que faculta a la Comisión Nacional de Valores a percibir tasas de fiscalización y control y aranceles de autorización para la oferta pública; la Comunicación "A" No 4353 del Banco Central de la República Argentina, referida a la prevención del lavado de dinero y otras actividades ilícitas; la Comunicación "A" No 42703 del Banco Central de la República Argentina, de redefinición de los requisitos aplicables a los fideicomisos financieros comprendidos en la Ley de Entidades Financieras; entre otras.

\footnotetext{
${ }^{3}$ Existen en este sentido legislaciones más flexibles, como la de nuestro país (Ley 24.441), que posibilita -como se verá- a cualquier persona física o jurídica constituirse como fiduciario (salvo en el caso del fideicomiso financiero, donde necesariamente debe tratarse de una entidad financiera regularmente constituida o una Sociedad autorizada por la Comisión Nacional de Valores), o mucho más rígidas, como la legislación paraguaya, que establece que solamente podrán tener la calidad de fiduciarios los bancos y empresas financieras y las empresas fiduciarias especialmente autorizadas por el Banco Central del Paraguay (Ley N 921, Art. 19).
} 
El artículo $1^{\circ}$ de la Ley 24.441," define claramente los lineamientos de este contrato cuando establece que "Habrá fideicomiso cuando una persona (fiduciante) transmita la propiedad fiduciaria de bienes determinados a otra (fiduciario), quien se obliga a ejercerla en beneficio de quien se designe en el contrato (beneficiario), y a transmitirlo al cumplimiento de un plazo o condición al fiduciante, al beneficiario o al fideicomisario".

Como puede apreciarse, el contrato de fideicomiso permite a una persona -denominada "fiduciante"- realizar un desprendimiento patrimonial a favor de otra -que se denomina "fiduciario"- constituyéndose de este modo un dominio fiduciario que será ejercido por este último por un período limitado de tiempo, a favor de quien se designe en el instrumento que le da nacimiento. Finalizado dicho período, los bienes pueden volver al fiduciante, destinarse al beneficiario, o bien terminar en poder del fideicomisario (que puede ser el beneficiario, un tercero o el mismo fiduciante).

Como bien señala Etchegaray (2011), "hasta el momento en que el fideicomiso fue introducido en el derecho positivo argentino, no había ningún otro medio para realizar actos de disposición de la propiedad que pudiese alcanzar un resultado parecido. Aunque fuese concebible que el dueño estableciese el destino de sus bienes en proyección de futuro, por acuerdo con un tercero, faltaban las normas que proveyeran la instrumentación necesaria y asegurasen el pleno reconocimiento de la manifestación de voluntad".

Es dable destacar que en esta materia rige con toda su fuerza el principio de autonomía de la voluntad. Si bien la Ley 24.441 establece determinadas condiciones y requisitos que deben cumplimentarse para la concreción de este contrato, su funcionamiento y particularidades estarán específicamente determinados de manera pormenorizada en las cláusulas del mismo, principalmente en cuanto a la forma de ejercicio de los bienes que constituyen la propiedad fiduciaria, por parte del fiduciario.

En cuanto a los caracteres de este contrato, la Cámara Nacional de Apelaciones en lo Comercial, Sala "C", en su sentencia del 19 de octubre del año 2007, en autos "New Cem SRL c/ Comafi Fiduciario Financiero S.A s/ ordinario"3 ha dicho que "la doctrina sostiene que el fideicomiso es el modo de adquirir el dominio fiduciario de una cosa con la condición de entregarla a quien se indique, luego de cumplida la condición o el plazo resolutorio impuesto. Se trata de un contrato consensual, bilateral, oneroso, de tracto sucesivo y que puede ser o no formal" (la negrita corresponde al autor del presente trabajo). A estos caracteres cabría agregar también que se trata de un contrato típico.

Es consensual, ya que se perfecciona por el mero acuerdo de voluntades entre las partes.

Se trata de un contrato bilateral, ya que se establecen obligaciones recíprocas para ambas partes, es decir, para el fiduciante y para el fiduciario.

Es oneroso, ya que existe una transmisión patrimonial de una parte a otra, debiéndose al fiduciario, además, una comisión por sus servicios. No obstante, este carácter presentaría para algunos autores una cierta relatividad, la cual ha sido resaltada por Borda (2008) al decir 
que "es complejo determinar si se trata de un contrato oneroso o gratuito. La transmisión fiduciaria, en sí misma, parecería realizarse a título gratuito, pues el fiduciante no recibe por la transmisión de los bienes contraprestación alguna. Sin embargo, desde la óptica del fiduciario, el negocio se presume oneroso -pues como regla- será retribuido (Art. $8^{\circ}$ ), aunque debe destacarse que tal retribución será pagada con los fondos fideicomitidos, excepto que hay a convenido que fuera afrontada por el propio fiduciante, o descontada de lo asignado al beneficiario o al fideicomisario según corresponda".

De tracto sucesivo o ejecución continuada, ya que las relaciones entre las partes se desenvuelven a través de un período más o menos prolongado de tiempo.

Puede ser o no formal, y ello dependerá de la naturaleza de los bienes que formarán el objeto del dominio fiduciario (V.gr. si entre los bienes existiera una cosa inmueble, debería formalizarse por medio de escritura pública). Por su parte, rige aquí también la exigencia del Art. 1193 del Código Civil que establece que "los contratos que tengan por objeto una cantidad de más de diez mil pesos, deben hacerse por escrito y no pueden ser probados por testigos"4.

Finalmente, es típico, por cuanto tiene una regulación específica, principalmente en la Ley 24.441 y demás legislación mencionada en los párrafos anteriores.

\section{SUJETOS Y OBJETO DEL CONTRATO}

En cuanto al aspecto subjetivo del contrato de fideicomiso, en nuestro sistema jurídico, y teniendo en cuenta la actual definición del mismo esbozada de manera muy clara por el Art. $1^{\circ} \mathrm{de}$ la Ley 24.441, puede apreciarse que en él intervienen cuatro partes bien diferenciadas, a saber: el fiduciante, constituido por aquel sujeto que transfiere a otra bienes determinados; el fiduciario, que es la parte a la cual se efectúa la transmisión de bienes referida, y que está obligada a obligada a administrarlos ${ }^{5}$, y que en nuestro Derecho - a diferencia de otros más rígidos- puede ser cualquier persona física o jurídica (con la salvedad hecha que para la constitución de un fideicomiso financiero, necesariamente debe tratarse de una entidad financiera, o bien una sociedad especialmente autorizada por la Comisión Nacional de Valores a esos fines); el beneficiario, que es aquella persona a favor o en beneficio de la cual se ha instituido el fideicomiso, y que pueden ser una o varias personas físicas o jurídicas; y el fideicomisario, quien es el destinatario final de los bienes (y que puede llegar a ser el mismo fiduciante, el beneficiario o un tercero).

En lo que respecta al aspecto objetivo del contrato de fideicomiso, la temática se vincula con el "patrimonio fiduciario", que representa una cuestión importante en esta materia.

El contrato, conforme lo señala el Art. 4 de la Ley 24.441, debe “individualizar" los bienes que integrarán el fideicomiso, o bien, si ello no resultara posible, describir los requisitos o las características que deberán reunir los bienes que constituirán el patrimonio fiduciario.

\footnotetext{
${ }^{4}$ No obstante, si tenemos en cuenta que en el año 1968 en que operó la reforma de la norma en cuestión por medio de la Ley 17.711, la moneda vigente (y sin perjuicio del caos de circulación monetaria de la época) era el Peso Moneda Nacional (m\$n), la suma mencionada en la norma equivale, en la actualidad, aproximadamente a 0,00000001 pesos, por lo que todos los contratos deberían celebrarse por escrito.

${ }^{5}$ Tomada la palabra "administrar" en sentido de ejercer la propiedad fiduciaria constituida, y no circunscripta a la actividad realizada en el fideicomiso de administración.
} 
Ello lleva a establecer una regla que, por lo demás parece ser la posición predominante en la doctrina de nuestro país, en el sentido que todo tipo de bienes puede constituirse en objeto de propiedad fiduciaria, siempre y cuando puedan individualizarse a fin de cumplir con el requisito de la norma aludida.

No obstante ello, y como lo señala Etchegaray (2011), "hay quienes piensan que, por tratarse de bienes determinados, que deben ser obligatoriamente individualizados en el contrato, la ley ha querido referirse a cosas precisas y determinadas, es decir, objetos materiales susceptibles de tener un valor (art. 2311. Cód. Civil); continuando con esa línea de pensamiento, restringen aún más el alcance del precepto legal y excluyen a las cosas fungibles y a las cosas consumibles".

Sin lugar a dudas que una posición tan restringida como la mencionada no resulta convincente, y menos aún a la luz del texto legal. Lo que la ley exige es la individualización inicial de los bienes a la hora de la constitución del fideicomiso y, de ser ello imposible en ese momento, manifiesta la necesidad de que se determinen los requisitos y características para su individualización futura, pero de ningún modo excluye a ningún tipo de cosas. Es lo que suele ocurrir en el campo obligacional, cuando no se determina de antemano de manera precisa el objeto de la obligación: el mismo debe estar determinado inicialmente, o bien puede establecerse los mecanismos para su determinación ulterior.

Resulta poco lógico pensar, por ejemplo, que los granos, no puedan ser objeto de un contrato de fideicomiso. Cabría inicialmente un grado de indeterminación inicial del objeto, que por lo general se referirá a la cantidad -V.gr., si dependiera de una cosecha-, pero el contrato será plenamente válido si se establecen algunas características referidas a su calidad y los requisitos para su determinación ulterior -en este caso los mecanismos para pesarlas, aunque bien podría ser para contarlas o medirlas según la clase de cosas fungible de que se trate-.

A raíz de lo expuesto rigen aquí, con pleno vigor, los Arts. 2311 y 2312 del Código Civil que establecen, recíprocamente, que "se llaman cosas en este Código, los objetos materiales susceptibles de valor...” y que "los bienes inmateriales susceptibles de valor, e igualmente las cosas, se llaman bienes" siendo estos, sin ningún tipo de distinción legal, los que pueden formar parte del contrato de fideicomiso.

\section{EL DOMINIO FIDUCIARIO}

Según el Art. 2662 CC, Ref. por la Ley 24.441, "es el que se adquiere en razón de un fideicomiso constituido por contrato o por testamento, y está sometido a durar solamente hasta la extinción del fideicomiso, para el efecto de entregar la cosa a quien corresponda según el contrato, el testamento o la ley".

En razón de ello, el fiduciario adquiere sobre los bienes un dominio imperfecto, y en este sentido, goza de todos los derechos y acciones propias del dominio pleno, diferenciándose de este, ya que fenece una vez cumplido el plazo que no puede exceder de 30 años, por imperativo legal del Art. 4, inc. c) de la Ley 24.441. 


\section{CLASES DE FIDEICOMISO}

El fideicomiso puede clasificarse teniendo en cuenta dos puntos de vista: según su forma y según la finalidad.

Si tenemos en consideración la forma de constitución del fideicomiso, podemos hablar de fideicomisos contractuales y fideicomisos testamentarios, según cuál sea el instrumento que se utilice para darle nacimiento.

Por su parte, si tomamos en cuenta la finalidad con la que se utilizará la herramienta, podemos hablar de tres clases bien diferenciadas, a saber:

El fideicomiso de administración, que es en el cual el fiduciante entrega determinados bienes al fiduciario para que éste los administre en beneficio de terceros o del propio fiduciante. Es el fideicomiso clásico y, como su nombre lo expresa, tiene como finalidad la administración de los bienes.

Por otro lado, el fideicomiso de garantía, que tiene como presupuesto necesario la existencia de una deuda del fiduciante con el fiduciario. En este sentido, para garantizar el cumplimiento de dicha obligación, el deudor (fiduciante) le entrega al acreedor (fiduciario) bienes para que este se cobre con el crédito de sus rentas o venta. En este caso, si bien el nombre del fideicomiso alude a una garantía, lo cierto es que constituye una suerte de forma de pago (semejante en su funcionamiento a la anticresis, aunque esta solo puede versar sobre inmuebles), el cual se garantiza o asegura por medio de la entrega de los bienes para su explotación.

Finalmente, el fideicomiso financiero, conforme lo señalan Varela y Guglielmetti (2008), es aquel en el cual se "emiten valores (títulos o certificados) contra el activo fiduciario y a favor de los beneficiarios". En este caso, solo puede ser fiduciario una entidad financiera o una Sociedad especialmente autorizada por la Comisión Nacional de Valores. La finalidad esencial de este contrato es la securitización de los créditos, a la que haremos referencia en los párrafos que siguen, como así también a esta figura en particular.

\section{ALGUNAS CUESTIONES REFERIDAS A LA SECURITIZACIÓN DE LOS CRÉDITOS: EL FIDEICOMISO FINANCIERO, SUS VENTAJAS Y DESVENTAJAS.}

Conforme lo señala Alegría (2010), la securitización "es un proceso de carácter financiero mediante el cual el titular de bienes (llamado a este efecto originante) los transmite a un vehículo con el fin de que éste emita sobre la base de ellos valores negociables susceptibles de ser colocados y/o negociados mediante oferta pública”.

No es el objetivo del presente apartado discurrir sobre las diferentes clases -tradicionales y no tradicionales- de securitización ya que ello excede el objeto central de análisis, constituido por brindar un panorama general acerca de la misma, especialmente mediante la utilización del fideicomiso financiero como vehículo.

La securitización permite, en su uso más corriente en nuestro país, unificar una masa de créditos -de distinta o igual naturaleza- que se dispongan contra deudores, mediante la cesión de los mismos a una entidad con capacidad para convertir esos créditos en valores cotiza- 
bles en el mercado, que se utiliza a modo de vehículo y que, como señala el autor mencionado, puede ser un fideicomiso -figura que veremos a continuación-, un fondo común de inversión, o una sociedad con objeto específico.

Como puede apreciarse, una de las formas de securitizar los créditos se da mediante la utilización del fideicomiso financiero.

Esta herramienta es definida por el Art. 19 de la Ley 24.441 como "aquel contrato de fideicomiso... en el cual el fiduciario es una entidad financiera o una sociedad especialmente autorizada por la Comisión Nacional de Valores para actuar como fiduciario financiero, y beneficiario son los titulares de certificados de participación en el dominio fiduciario o de títulos representativos de deuda garantizados con los bienes así transmitidos".

Como se había expresado, en nuestro Derecho, como principio general, puede constituirse como fiduciario cualquier persona física o jurídica. No obstante, la regla mencionada tiene su excepción a la hora de hablar del fideicomiso financiero ya que aquí, para poder ejercer el dominio fiduciario que se genera con la transmisión de los créditos del originante al vehículo -que en este caso es un fideicomiso- debe, necesariamente, tratarse de entidad financiera o bien una sociedad especialmente autorizada.

En este caso, al igual que en las otras modalidades de securitización de activos, existe un originante que cede una masa de créditos a un ente con potestad para emitir valores representativos de los mismos, que sean susceptibles de colocarse en el mercado, a fin de que sean adquiridos por los inversores.

Este instrumento representa, sin lugar a dudas, una herramienta de singular importancia para el desarrollo y crecimiento de las empresas o grupos económicos, que se utiliza cada vez más.

Esto puede apreciarse muy claramente con el ejemplo del "Grupo Carsa" (integrado por las firmas Megatone, Musimundo, Corefin, Reposar y Aliado), que ha venido utilizando esta herramienta desde el año 2003.

En este sentido, la economía de los establecimientos comerciales se asienta, básicamente, sobre dos pilares fundamentales: el capital propio (es decir, su patrimonio neto), y los créditos que se tengan frente a terceros (es decir, los pasivos). Esos créditos (mayormente hipotecarios, prendarios, o al consumo, entre otros) suelen estar inmovilizados, ya que el empresario no podrá contar con los ingresos en efectivo que puedan derivar de los mismos, hasta tanto no se vayan venciendo las respectivas cuotas correspondientes a las financiaciones acordadas por los créditos otorgados.

Pues bien, el fideicomiso financiero sirve como motor financiero de las empresas, permitiéndole contar con una liquidez cada vez mayor, permitiéndoles utilizar menor cantidad de activo propio, y más pasivos, representados por los créditos disponibles frente a terceros.

El cuadro ${ }^{6}$ que se puede ver a continuación, resume claramente la situación del grupo económico mencionado ut supra. Como puede verse, en el plazo de 8 años, la empresa hizo

\footnotetext{
${ }^{6}$ Cuadro extraído de la presentación del Cr. Silvio F. Varrone, Director de Administración y Finanzas del Grupo CARSA, en su exposición "Fideicomiso Financiero", realizada en oportunidad de la presentación del Departamento de Fideicomisos de la Bolsa de Comercio del Chaco, realizada el día 29 de noviembre del año 2011 en el Consejo de Profesionales de Ciencias Económicas, Resistencia, Provincia del Chaco.
} 
crecer 13 veces su capital, disminuyendo el uso de su propio capital para aprovechar los créditos que disponían inmovilizados.

\section{Apalancamiento Financiero}

\section{INVERSIÓN TT <ACTIVO>}

Quien la financia
CAPITAL PROPIO <PN>
TERCEROS <PASIVO>
* Proveedores Nacionales y Extranjeros
* Fisicos
* Bancos
* Mercado de Capitales o Valores <F.F.+ON >
* Mercado de Capitales o Valores <Emisión Acciones>

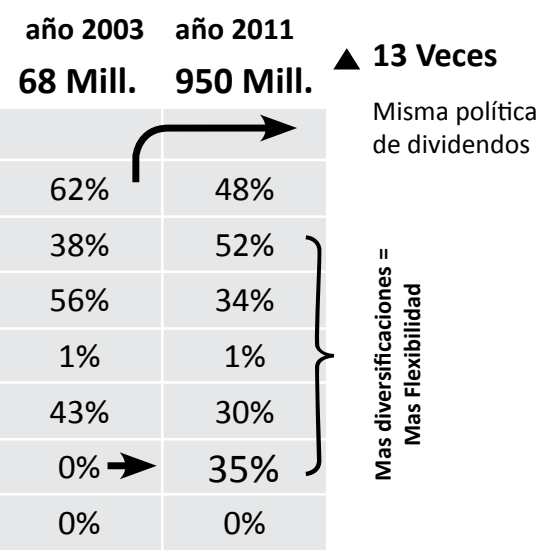

Esta figura jurídica tiene amplias ventajas, no sólo para el originante del fideicomiso que, como se pudo apreciar, puede hacer un uso eficiente de activos que tiene inmóviles, constituyendo ello una palanca financiera de la misma, sino también para otros actores que intervienen en el proceso de la securitización.

En este sentido, los inversores que adquieren los valores que representan la deuda, lo hacen sobre créditos "seguros" ya que los mismos se aíslan del giro del originante, ante lo cual quedan cubiertos esos créditos de eventuales concursos y quiebras -sin perjuicio de las discusiones al respecto-.

Asimismo, los demás intervinientes en el proceso (fiduciarios, agentes depositarios de los títulos, calificadoras de riesgos, entre otros) perciben comisiones y honorarios por sus actividades.

En cuanto a las desventajas, puede decirse que no es una herramienta disponible para cualquier emprendimiento, sino que más bien deberá tratarse de un emprendimiento en marcha, que lleve adelante un negocio o actividad consistente, sostenible en el tiempo, que genere un flujo permanente de activos, y que a su vez sean más o menos predecibles, a fin de dar mayor seguridad a los valores lanzados al mercado.

Otra de las desventajas, radica en la complejidad en la instrumentación del fideicomiso financiero, el cual parece ser muy sencillo cuando se lo describe de manera general, pero que resulta ser todo un proceso en el que intervienen diferentes actores, con modalidades contractuales complicadas, sin poder dejarse de lado, obviamente, las cuestiones impositivas que también alcanzan al mismo. 
Finalmente, el fideicomiso financiero no está exento de los riesgos económicos, por lo que, como cualquier otra inversión, no es cien por ciento segura. En este sentido, merece destacarse que se debe poner especial atención en la calidad de créditos securitizados, a fin de evitar contribuir al desarrollo de crisis económicas, como la ocurrida -entre otras causales no menos importantes- por la securitización de hipotecas subprime otorgadas en Estados Unidos, y luego colocadas por medio de diferentes vehículos al mercado financiero mundial.

\section{CONCLUSIÓN}

En el presente, hemos analizado de manera general la modalidad contractual denominada fideicomiso, a la cual la doctrina suele incluir en el catálogo de los "contratos modernos".

Asimismo, se ha hecho especial hincapié en la securitización de activos a través de la utilización del fideicomiso financiero, ya que va ganando cada vez más terreno como herramienta de posicionamiento y de palanca financiera de las grandes empresas, como bien pudo apreciarse en el ejemplo empírico brindado en el punto anterior.

Sin lugar a dudas que la utilización de esta figura se difundirá cada vez más en nuestro país, dando acceso a la misma a negocios de mediano tamaño.

Ello implica que necesariamente deban los juristas preocuparse por la búsqueda de la mejora en el funcionamiento actual del sistema, proponiendo, de ser necesario, las adaptaciones legislativas correspondientes a fin de mantener un orden en esta materia, que en gran parte está librada a la autonomía de la voluntad.

Tal como lo señala Alegría (2010) - al referirse al futuro de esta herramienta (de la cual uno de sus principales vehículos lo constituye el fideicomiso financiero)- "se ha dicho que el futuro de la securitización es seguro y que ello puede afirmarse también después de los sucesos del caso Enron y similares. Es probable que los sucesos antes mencionados hayan impactado incluso en nuestros mercados, pero mirando la cuestión desde la mitad de la botella llena y con razonable perspectiva, podemos decir que todos los mercados pueden tomar experiencias y ganar en seguridad, perfeccionando las leyes y las instituciones al tiempo que el trasfondo económico mejora el horizonte y la visión de los críticos, incluso de los juristas, y termina siendo más positiva para la interpretación integral de los fenómenos”.

En ello radica entonces la consigna: valerse de las experiencias ajenas para mejorar la institución en nuestro sistema, evitando caer en los mismos errores, y garantizando de este modo la mayor seguridad jurídica y económica posible en su utilización. 


\section{REFERENCIAS BIBLIOGRÁFICAS.}

Alegría H. (2010). Securitización. En F. Junyent Bas, y C. A. Molina Sandoval, (Eds.), Curso de Derecho Cambiario (Capítulo VII, pp. 225-264). Córdoba: Ed. Advocatus.

Borda, G. A. (2008). Manual de Derecho Civil - Contratos, $21^{\circ}$ Edición actualizada por Alejandro Borda. Buenos Aires: Ed. La Ley.

Etchegaray, N. P. (2011): Fideicomiso. Buenos Aires: Ed. Astrea.

Ferretti, A. T. (1992). Derecho Romano Patrimonial. México D.F.: Ed. Universidad Nacional Autónoma de México.

García del Corral, I. L. (1889). Cuerpo del Derecho Civil Romano, Primera Parte. Barcelona: Ed. Jaime Molinas.

Icazatti, M. (2011). Fideicomiso Financiero. Buenos Aires: Revista de Derecho Comercial del Consumidor y de la Empresa, Ed. La Ley, Año II, $\mathrm{N}^{\circ} 2$.

Varela, M. G., Guglielmetti, L. (2008). Fideicomisos. Buenos Aires: Ed. Aplicación Tributaria S.A.

\section{CURRÍCULUM VITAE}

SERGIO JUNIORS SHWOIHORT.

Título de Grado: Abogado.

Máximo grado académico alcanzado: Máster en Política y Gestión Universitaria.

Cargos Académicos: Profesor Adjunto por Concurso en la Cátedra de Instituciones del Derecho Privado II de la Facultad de Ciencias Económicas de la UNNE; Profesor Libre de la Cátedra "B" de Derecho Civil II de la Facultad de Derecho y Ciencias Sociales y Políticas de la UNNE; Auxiliar Docente de Primera de Instituciones del Derecho Privado I de la Facultad de Ciencias Económicas de la UNNE.

Cargo científico: Investigador de Posgrado de la Secretaría General de Ciencia y Técnica de la UNNE, categoría perfeccionamiento.

sergiojuniors@hotmail.com 